\title{
A Case of Treated Penile Melanoma with Gastric Recurrence
}

\author{
Gabriel Melki ${ }^{1, *}$, Hadir Mohamed ${ }^{1}$, Ashima Kapoor ${ }^{1}$, Jewook Ha ${ }^{1}$, \\ Abdalla Mohamed ${ }^{2}$, Varun Patel ${ }^{2}$, Walid J. Baddoura ${ }^{2}$
}

1. Department of Internal Medicine, St. Joseph's University Medical Center, Paterson, NJ, USA

2. Department of Gastroenterology, St. Joseph's University Medical Center, Paterson, NJ, USA

\footnotetext{
* Corresponding Author:

Gabriel Melki, MD

703 Main Street, Paterson, New Jersey

07503, United States of America

Tel: + 9737542439

Fax: $+9732243-2570$

Email: gabriel.melki@mail.mcgill.ca

Received: 18 Dec. 2020

Accepted: 11 Mar. 2021
}

\section{ABSTRACT}

Melanoma is a very aggressive skin cancer that could metastasize to any organ in the body. The treatment of melanomas includes surgical resection, chemotherapy, and immunotherapy. After resections, melanomas could recur at the previous site or present as a distant metastatic lesion. The symptoms of melanoma are vague and primarily occur because of the local disruption of the tissue architecture. Presented here is a case of gastric melanoma that presented with abdominal discomfort and melena in a patient with a history of penile melanoma that was completely resected 3 years earlier. This case illustrates the importance of having metastatic lesions to the intestinal tract as a differential for a patient with gastrointestinal hemorrhage.

\section{KEYWORDS:}

Melanoma, Gastric Melanoma, Melena, Upper GI Bleed

Please cite this paper as:

Melki G, Mohamed H, Kapoor A, Ha J, Mohamed A, Patel V, Baddoura JW. A Case of Treated Penile Melanoma with Gastric Recurrence. Middle East J Dig Dis 2021;13:258262. doi: $10.34172 /$ mejdd.2021.233.

\section{INTRODUCTION}

Melanoma is the most aggressive form of skin cancer and has the potential to metastasize to any organ in the body. While some metastatic sites like the lungs, central nervous system (CNS), and lymph nodes are more frequently observed, metastasis to the stomach is a rare entity. ${ }^{1}$ Furthermore, due to vague and non-specific symptoms, metastatic gastric tumors remain undetected until autopsy. ${ }^{2}$ Penile melanoma as a primary or metastatic cancer is extremely rare, accounting for less than $0.7 \%$ of penile cancers. ${ }^{3}$ In this case report, we describe an unusual case of primary penile melanoma with metastasis to the gastric mucosa. The behavior of melanoma and its spread has been well described in the literature; we present a case where the primary and metastatic lesions are both in unusual sites.

\section{CASE REPORT}

A 73-year-old man with a history of penile melanoma, who had undergone partial penilectomy and chemotherapy with remission, presented to the emergency department with a chief complaint of dizziness and blacktarry stool for 3 days. In the emergency department, the patient was 

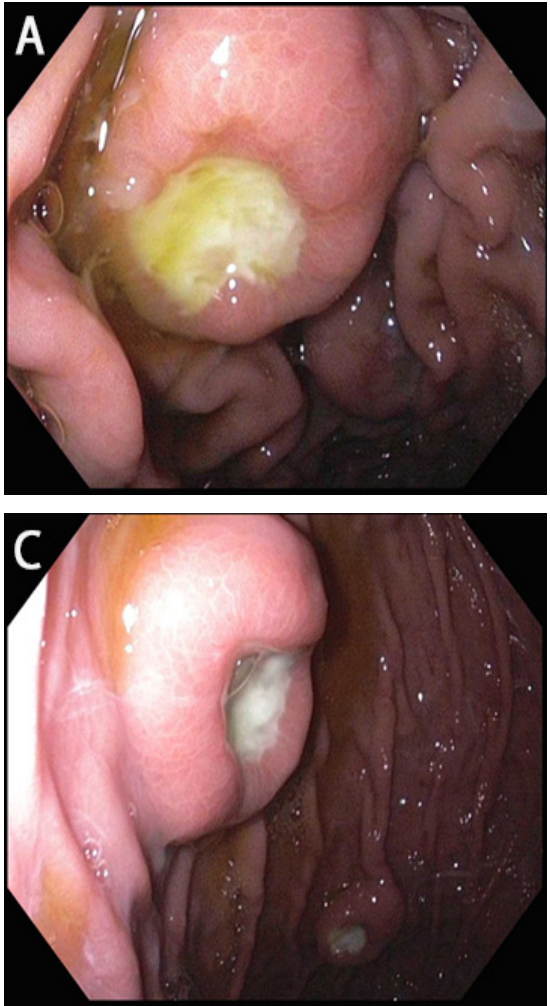
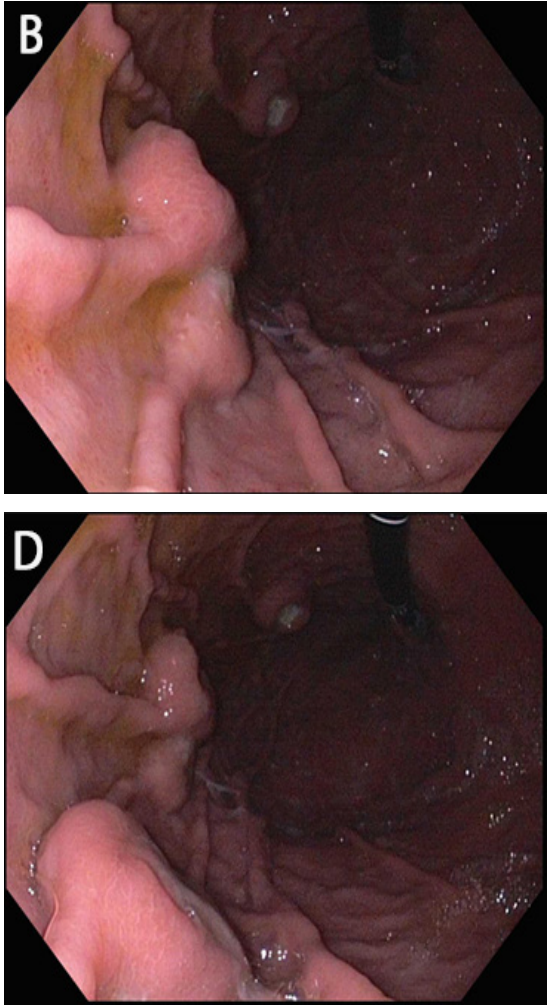

Fig. 1 A-D: Endoscopic images depicting the ulcerated masses, approximately $0.5 \mathrm{~cm}$ in size hypotensive and tachycardic. A rectal exam revealed black stool, which was guaiac positive. A penile exam revealed a surgical scar on the ventral side of the penis, and the remainder of the physical exam was unremarkable. Laboratory tests revealed a hemoglobin of $9.2(\mathrm{~g} / \mathrm{dL})$, hematocrit $27.9 \%$ (L/L), and MCV of 86.0, BUN: $30(\mathrm{mg} / \mathrm{dL})$ and $\mathrm{Cr}$ : $0.82(\mathrm{mg} / \mathrm{dL})$. Due to hemodynamic instability, the patient was admitted to the medical intensive care unit and transfused one unit of packed red blood cells (PRBC), and started on intravenous pantoprazole. Given the high probability of an upper gastrointestinal bleed, an esophagogastroduodenoscopy (EGD) was performed, which revealed four separate $0.5 \mathrm{~cm}$, ulcerated, submucosal masses with no active bleeding in the greater curvature of the stomach (figures 1). Cold forceps biopsies were taken, which eventually revealed metastatic malignant melanoma with extensive necrosis. The metastatic melanoma cells diffusely infiltrated the lamina propria and submucosa. The tumor cells were positive for Melanoma Antigen Recognized by $\mathrm{T}$ cells (MART-1) (figures
2-3). Computed tomography (CT) of the chest, abdomen, and pelvis was ordered to assess for any other metastatic lesions. CT of the chest revealed a single large aortopulmonary window lymph node on the right side measuring $2.7 \times 2.5 \mathrm{~cm}$ and other smaller reactive lymph nodes. CT of the abdomen and pelvis revealed a large left posterior gastric fungating mass, mostly exophytic, with infiltration of the greater curvature measuring $10 \times 10 \times 11 \mathrm{~cm}$ (figures 4 ). The patient received a total of one unit of $\mathrm{PRBC}$, responded appropriately to transfusion, and remained hemodynamically stable, and eventually was transferred to general medical wards.

\section{DISCUSSION}

Primary sites of melanoma usually involve the skin of the extremities, followed by the trunk, and finally the head and neck. ${ }^{4}$ Primary penile melanoma is an extremely rare malignancy that accounts for less than $2 \%$ of all primary penile malignant lesions. ${ }^{4}$ Malignant melanoma has the potential to metastasize to any part of the body. Secondary neoplasms of the stomach are rare and are difficult to 


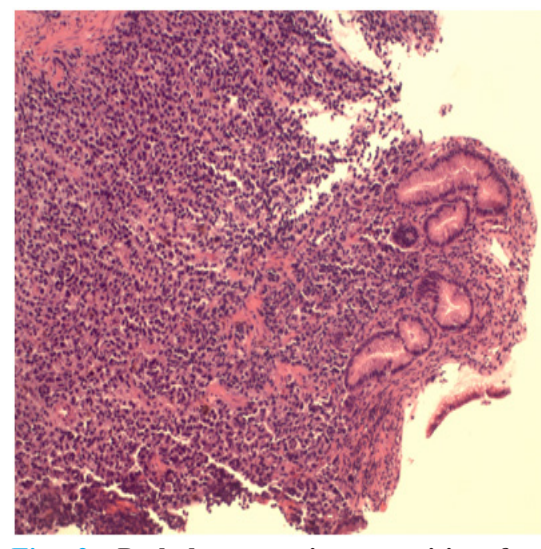

Fig. 2: Pathology specimen positive for metastatic malignant melanoma with extensive necrosis.

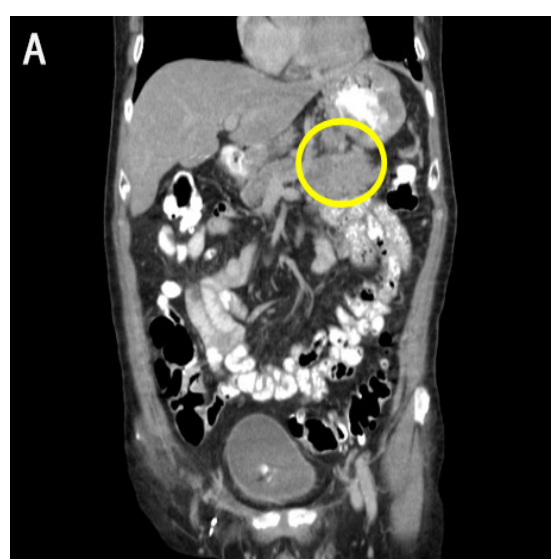

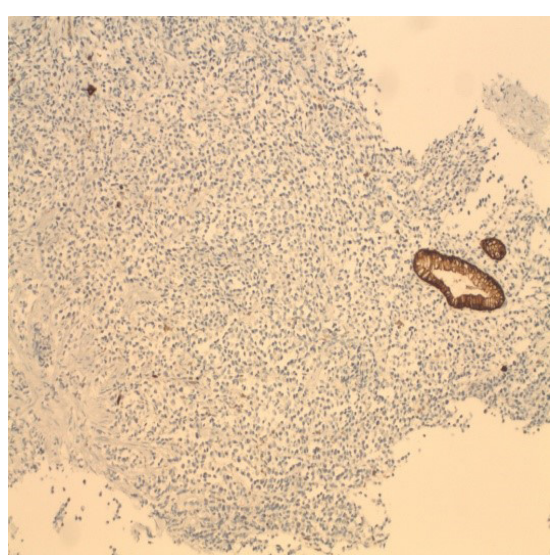

Fig. 3: Pathology immunostains showing cells positive for MART-1

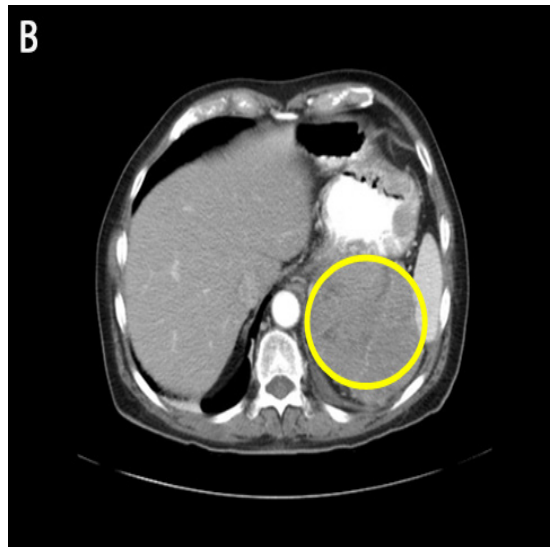

Fig. 4: Coronal and transverse computed tomography of the abdomen and pelvis showing a large exophytic mass posterior to the stomach.

diagnose because patients are usually asymptomatic. ${ }^{5}$ Malignant melanoma metastases in the gastrointestinal tract are detected clinically in only $2 \%$ of the cases. ${ }^{6,7,8}$ However, they are found in more than $60 \%$ of autopsies on patients who have died with disseminated melanoma . ${ }^{7,8}$ The most common site for melanoma to metastasize to the gastrointestinal tract is the small bowel (35\%-97\%), followed by the stomach and duodenum $(5-50 \%){ }^{7,8}$ Given the absence of melanocytes in the stomach, gastric melanoma is believed to originate from ectopic melanocytes that migrate to the gastrointestinal tract during embryogenesis or differentiation of amine precursor uptake and decarboxylation cells to melanocytes. ${ }^{7}$ Symptoms mainly include gastrointestinal bleeding, abdominal pain, anorexia, nausea, vomiting, weight loss, dysphagia, obstruction, and occasionally acute perforation. ${ }^{10}$ Our patient presented with the sole complaint of melena.
The workup of an intra abdominal lesion includes both imaging and endoscopy ${ }^{9,10,11} \mathrm{CT}$ is commonly used to detect intra-abdominal lesions. Positron emission tomography (PET)/CT has also been shown to have higher sensitivity and accuracy in the detection of visceral metastases, including extra-intestinal metastatic disease. ${ }^{9}$ Patients who present with gastrointestinal symptoms or display abnormal imaging should undergo endoscopic evaluation. This allows for direct visualization and potential diagnostic biopsy for a pathological diagnosis.$^{11}$

The endoscopic classification of gastric metastases comprises three main morphological types. ${ }^{12}$ Firstly, there are melanotic nodules, often ulcerated at the tip, which are the most frequently observed endoscopic feature. Secondly, there are submucosal tumor masses, melanotic or not, which are elevated and ulcerated at the apex. This is the typical aspect of "bull's eye" lesions. 
The third morphological type is a mass lesion, which may have varying degrees of necrosis and melanosis. ${ }^{13}$ Our patient would be classified into the first category. Size does not play as much of a role in prognosis as compared with depth and invasion, which proves to be more important in staging and prognosis. ${ }^{14}$ In primary gastric melanomas, the initial lesion thickness less than $0.75 \mathrm{~cm}$ is associated with excellent survival rates and a low risk of metastasis. ${ }^{15}$

Treatment of metastatic melanoma to the gastrointestinal tract may include surgical resection, chemotherapy, immunotherapy, biochemotherapy or observation. ${ }^{16}$ Wornom and colleagues reported on the outcomes of 65 patients who underwent surgical excision of 94 metastatic lesions from various sites, including the brain, lung, abdomen, distant subcutaneous sites, and distant lymph nodes. Median survival ranged from 8 to 15 months in the various subgroups, and $16 \%$ of patients lived for 2 years or longer. ${ }^{17}$ Ollila and co-workers retrospectively evaluated the role of surgery in the survival of patients with melanoma metastatic to the gastrointestinal tract. Of the 124 patients, 69 (55\%) underwent surgical exploration of the abdomen, $46(66 \%)$ had a curative resection, and $23(34 \%)$ had a palliative procedure. Sixty-seven (97\%) of 69 surgical patients experienced postoperative relief of their presenting gastrointestinal symptoms. The median survival in patients undergoing curative resection was 48.9 months, compared with only 5.4 months and 5.7 months in those undergoing palliative procedures and non-surgical interventions, respectively. ${ }^{18}$ Although there are some studies looking at neoadjuvant treatment, there are still no definitive studies suggesting improvement in survival of patients with chemotherapy. ${ }^{19}$

Surgical resection is the only identifiable treatment modality for which independent predictive prognostic values have been demonstrated. ${ }^{15}$ The main predictive factors of survival after curative resection include the site of metastasis, number of metastatic lesions, and the disease-free interval prior to the development of metastasis. ${ }^{19}$ Systemic chemotherapy regimens show no benefit in overall survival and are not recommended for the treatment of malignant gastrointestinal melanomas. ${ }^{19}$ Due to the high recurrence rate of metastatic melanoma, oncologic follow-up with periodic PET scan is recommended. Other exams such as upper endoscopy, colonoscopy, and CT are repeated as clinically indicated. ${ }^{20}$
Secondary gastric melanomas are usually diagnosed at the time of autopsy. ${ }^{7,8}$ This case depicts a rare case of penile melanoma, which was resected and underwent chemotherapy; however, it presented 3 years post-operatively with tests showing isolated gastric recurrence. This case illustrates the need to always consider the recurrence of melanoma in the differential diagnosis, regardless of the primary site and treatment success of the melanoma in a patient presenting with gastrointestinal symptoms.

\section{ACKNOWLEDGEMENT}

We thank Dr. Patrick Michael (Program Director of the Internal Medicine Residency), Dr. Michael Agnelli (Associate Program Director of the Internal Medicine Residency), Dr. Monisha Singhal (Associate Program Director of the Internal Medicine Residency) and Dr. Robert Lahita (Chairman of the Department of Medicine) for their continuous support and guidance.

\section{Financial Disclosure or Funding}

No funding was provided to any of the authors

\section{ETHICAL APPROVAL}

There is nothing to be declared.

\section{CONFLICT OF INTEREST}

The authors declare that they have no conflicts of interest.

\section{Informed Consent}

Informed consent was obtained from the patient for this case report.

\section{Author contributions}

All authors contributed to the revision and approval of the manuscript.

\section{REFERENCES}

1. Patel JK, Didolkar MS, Pickren JW, Moore RH. Metastatic pattern of malignant melanoma. A study of 216 autopsy cases. Am J Surg 1978;135:807- 10. doi: 10.1016/0002-9610(78)90171-x.

2. Wong K, Serafi SW, Bhatia AS, Ibarra I, Allen EA. Melanoma with gastric metastases. J Community Hosp Intern Med Perspect 2016;6:31972. doi: 10.3402/jchimp. v6.31972. eCollection 2016. 
3. Jabiles AG, Del Mar EY, Perez GAD, Vera FQ, Montoya LM, Deza CMM. Penile melanoma: a 20-Year analysis of six patients at the National Cancer Institute of Peru, Lima. Ecancermedicalscience 2017;11:731. doi: 10.3332/ecancer.2017.731.

4. Retsas S, Christofyllakis C. Melanoma involving the gastrointestinal tract. Anticancer Res 2001;21:1503-8.

5. Stillwell TJ, Zincke H, Gaffey TA, Woods JE: Malignant melanoma of the penis. J Urol 1998;140:72-5. doi: 10.1016/s0022-5347(17)41490-x.

6. Daniela A. Benedet-Stojanov, Aleksander v. Nagorni, Vesna V. Zivkovic, Jovica R. Milanovic, Dragan A. Stojanov: Metastatic melanoma of the stomach and duodenum. Case Report. Arch Oncol 2006;14:60-1.

7. Oda HK, Yamao TS, Ono HG, Gotoda TY, Yamaguchin HY, Yoshida S, et al. Metastatic tumors to the stomach: analysis of 54 patients diagnosed at enoscopy and 347 autopsy cases. Endoscopy 2001;33:507-10. doi: $10.1055 / \mathrm{s}-2001-14960$.

8. Marin M, Vlad L, Grigorescu M, Sparchez Z, Dumitra D, Muti L. Metastasis of malignant melanoma in the small intestine. A case report. Rom J Gastroenterol 2002;11:53-6.

9. Marsden JR, Newton-Bishop JA, Burrows L, Cook M, Cor-rie PG, Cox NH, et al; British Association of Dermatologists Clinical Standards Unit. Revised U.K. guidelines for the management of cutaneous melanoma 2010. Br J Dermatol 2010;163:238-56. doi: 10.1111/j.1365-2133.2010.09883.x.

10. Goral V, Ucmak F, Yildirim S, Barutcu S, Ileri S, Aslan I, et al. Malignant melanoma of the stomach presenting in a woman: a case report. J Med Case Rep 2011;5:94. doi: 10.1186/1752-1947-5-94.

11. Taal BG, Westerman H, Boot H, Rankin EM .Clinical and endoscopic features of melanoma metastases in the upper GI tract. Gastrointest Endosc 1999;50:2613. 10.1016/S0016-5107(99)70236-1.

12. Iconomou TG, Tsoutsos D, Frangia K, Gogas H, Papadopoulos S, Georgountzos V, et al. Malignant melanoma of the stomach presenting with an unknown primary lesion. Eur J Plast Surg 2003;26:153-5. doi:10.1007/s00238-003-0497-6.

13. Wong K, Serafi SW, Bhatia AS, Ibarra I, Allen EA. Melanoma with gastric metastases. JCommunity Hosp Intern Med Perspect 2016;6:31972. doi: 10.3402/jchimp. v6.31972. eCollection 2016.

14. Roder JD, Bottcher K, Busch R, Wittekind C, Hermanek $\mathrm{P}$, Siewert JR. Classification of regional lymph node metastasis from gastric carcinoma. German Cancer Study Group. Cancer 1998;82:621-31.

15. Schmid-Wendtner MH, Baumert J, Eberle J, Plewig G, Volkenandt M, Sander CA. Disease progression in patients with thin cutaneous melanomas (tumour thickness $>0.75 \mathrm{~mm}$ ): clinical and epidemiological data from the Tumour Center Munich 1977-98. Br J Dermatol 2003;149:788-93. doi: 10.1046/j.1365- 2133.2003.05599.x.

16. Schuchter LM, Green R, Fraker D. Primary and metastatic diseases in malignant melanoma of the gastrointestinal tract. Curr Opin Oncol 2000;12:1815. doi: 10.1097/00001622-200003000-00014.

17. Wornom IL III, Smith JW, Soong SJ, McElvein R, Urist MM, Balch CM. Surgery as palliative treatment for distant metastases of melanoma. Ann Surg 1986;204:181-5. doi: 10.1097/00000658-19860800000013 .

18. Ollila DW, Essner R, Wanek LA, Morton DL. Surgical resection for melanoma metastatic to the gastrointestinal tract. Arch Surg 1996;131:979-80. doi: 10.1001/archsurg.1996.01430210073013.

19. Reintgen DS, Thompson W, Garbutt J, Seigler HF. Radiologic, endoscopic, and surgical considerations of melanoma metastatic to the gastrointestinal tract. Surgery 1984;95:635-9.

20. Rocha ME, Rodrigues GP, Borges SA, Santiago FG. Metastatic melanoma of the stomach. ABCD. Arquivos Brasileiros de Cirurgia Digestiva (São Paulo) 2008;21:205-7. doi: 10.1590/S010267202008000400010 . 